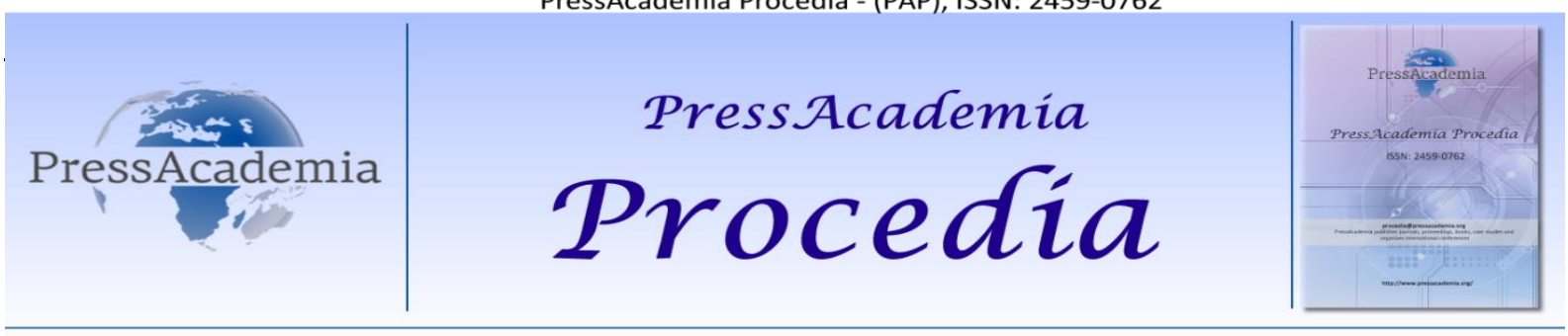

Global Business Research Congress (GBRC), May 24-25, 2017, Istanbul, Turkey.

\title{
VALUATION OF SECURITIES WITH RESPECT TO TURKISH FINANCIAL REPORTING STANDARDS AND TAX PROCEDURE LAW AND THEIR IMPACTS ON THE REPORTING
}

\author{
DOI: 10.17261/Pressacademia.2017.680 \\ PAP-GBRC-V.3-2017(107)-p.1000-1011 \\ Huseyin Mert ${ }^{1}$, Guler Karak ${ }^{2}$ \\ ${ }^{1}$ Okan University. huseyin.mert@okan.edu.tr \\ 20kan Univeristy.gulerkarak@gmail.com
}

\section{To cite this document}

Mert, H. and M.Eren, (2017). Valuation of securities with respect to Turkish financial reporting standards and tax procedure law and their impacts on the reporting. PressAcademia Procedia (PAP), V.3, p.1000- 1011.

Permemant link to this document: http://doi.org/10.17261/Pressacademia.2017.680

Copyright: Published by PressAcademia and limited licenced re-use rights only.

\begin{abstract}
Valuation occupies a significant place in life as a common measure is required in mutual economic relationships. Regulations on valuation bear some differences with respect to the Tax Procedure Law and Turkish Financial Reporting Standards. Valuation of Securities that are among the financial instruments also bears some differences with respect to the Tax Procedure Law and Turkish Financial Reporting Standards practices. Tax Procedure Law did not include multiple valuation criteria in valuation of the Securities and did not provided enterprises with any different opportunity. However, according to the Turkish Financial Reporting Standards measuring terms, alternative valuation measures may be used. Therefore, amount of the commercial profits changes. Balance sheets of the enterprises give the closest results to the reality. Benefits and what are brought by the valuation differences occurred as a result of measuring and recognizing the Securities were analyzed. Application differences between the Turkish Financial Reporting Standards, their impacts on the financial statements of the enterprises and corrections increase importance of the accounting policies.Purpose of this study is to analyze the valuation of the securities that are important for the enterprises with respect to the Tax Procedure Law and Turkish Financial Reporting Standards and to reveal their impacts on the reporting.
\end{abstract}

Keywords: Turkish Financial Reporting Standards, Tax Procedure Law, valuation of securities.

JEL Codes: M41, M42

TFRS VE VUK'NU YÖNÜNDEN MENKUL KIYMETLERIN DEĞERLEMESI VE RAPORLAMAYA ETKILERI

\section{ÖZET}

Değerleme; karşılıkı ekonomik ilişkilerde, ortak bir ölçüye ihtiyaç duyulması yönünden yaşamda önemli bir yere sahiptir. Değerlemeye iliş̧in düzenlemeler V.U.K. ve TFRS yönünden farklılıklar içermektedir. Finansal araçlardan olan Menkul Kıymetlerin değerlemesi de, VUK ve TFRS uygulamaları yönünden farklılıklar gösterir. Vergi Usul Kanunu Menkul Kıymetlerin değerlemesinde birden fazla değerleme ölçüsüne yer vermiyor ve işletmelere herhangi farklı imkanlar sağlamıyordu Fakat Türkiye Finansal Raporlama Standartları ölçüm esaslarına göre, alternatifli değerleme ölçüleri kullanılabiliyor. Bu nedenle de ticari karların tutarı değişmektedir. İşletmelerin bilançoları gerçeğe en yakın sonuçları vermektedir. Menkul Kıymetlerin ölçme ve muhasebeleştirilmesi sonucunda oluşan değerleme farklarının getirdikleri ve faydaları incelenmiştir. Türkiye Finansal Raporlama Standartları arasındaki uygulama farklılıkları işletmelerin finansal tablolarına etkileri ile ve düzeltmeler muhasebe uygulamalarının önemini artırmaktadır. Bu çalışmada amaç; işletmeler için önemli olan menkul kıymetlerin değerlemesinin, Vergi Usul Kanunu ve Türkiye Finansal Raporlama Standartları yönünden incelenmesi ve raporlamaya etkilerinin ortaya çıkartılmasıdır.

Anahtar Kelimeler: Türkiye Finansal raporlama Standartları, Vergi Usul Kanunu, Menkul Kıymetlerin Değerlemesi,

JEL Kodları: M41, M42 


\section{Giriş}

Dünyada Ekonominin küreselleşmesi ile birlikte şirketlerin ve muhasebe uygulayıcılarının karşılaştıkları farklılıklar her geçen gün artmakta olduğundan Türkiye'deki düzenlemelerin ve uluslar arası düzenlemelerin ortak bir noktada bu değişimleri yakalaması gerekir. Vergi Usul Kanunu'nun değerlemeye ilişkin bazı hükümleri ile Türkiye Finansal Raporlama Standarttı ile bazı hükümleri birbiriyle uyumlu bazıları farklılıklar gösterir.

TFRS farklı ülkelerdeki şirketlerin mali performanslarının karşılaştırılabilirliğini arttırmakta ve böylece yatırımcılar açısından mali bilgi maliyetini azaltır. Bu unsurlar yatırımcıların daha doğru kararlar almalarını sağlar.

\section{MENKUL KIYMETLER}

Menkul Kıymetler, seri halinde çıkarılan belirli bir tutarı temsil eden yatırım aracı olarak kullanılan, dönemsel gelir getiren ortaklık veya alacaklıık sağlayan kıymetli evraktır. Her birinin bir itibari (Nominal üzerinde yazıı) değeri ve piyasa da arz ve talebin oluşturduğu piyasa değeri vardır. Menkul kıymetlerin sürekli alınıp satıldığı bir piyasası vardır. Çok sayıda ihraç edilip halka arz edilen kıymetlerdir. Sermaye Piyasası Kurulu tarafından belirlenen kıymetli evraktır. Menkul kıymetler spekülatif amaçlar için daha çok kullanılır. Menkul Kıymetler iktisadi bakımdan en çok kullanılan türleri, tahvil, Hazine bonosu, hisse senedidir. Ayrıca yatırım fonu katılma belgesi, kar-zarar ortaklığı belgesi, gelir ortaklığı senedi gibi kıymetlerden oluşur. Ekonomideki gelişmelerin paralelinde menkul kıymetlerin çeşitlerinde artış olmuştur. Çok sayıda ihraç edilip halka arz edilen kitle senetleridir. Menkul kıymetler, Nama veya Hamiline yazılı olabilirler. Hamiline yazılı kıymetler para gibidir kimin elinde olursa o kişinin sayılır. Sadece teslimle sahip değiştirir. Nama yazılı kıymetlerde ise ciro hanesi vardır. Ciro işlemi kaydedilir.

\section{Sermaye Piyasası Kanunu'na göre Menkul Kıymetler}

- Hisse senetleri ve geçici ilmühaberleri,

- Tahvil, İntifa senedi,

- Kar ve zarar ortaklığı belgeleri,

- Hazine bonoları, devlet ve diğer kamu tüzel kişilerinin tahvil ve bonoları, gelir ortaklığı senetleri,

- $\quad$ Tertip halinde çıkarılan ve 2 yıl veya daha uzun süreli ipotekli borç ve irat senetleridir

Sermaye Piyasası Kanunu'na göre Menkul Kıymet Sayılmayanlar

- Finansman bonoları, banka bonoları, banka garantili bonolar,

- Faiz kuponu, temettü kuponu, Talon,

- 2 yıldan az süreli ve tertip halinde çıkarılan ipotekli borç ve irat senetleri,

- Yatırım fonu katılma belgeleri, (A tipi fonların katılma belgeleri menkul kıymet sayılmaktadır)

- Maliklerince düzenlenen opsiyon senetleri,

- Mevduat sertifikalarıdır.

Bunların dışında Sermaye Piyasası Kurulu tarafından belirlenecek sermaye piyasası araçları da bu anlamda işlem görürler. Bu duruma göre menkul kıymet sayılan ya da sayılmayan, fakat sermaye piyasasında menkul kıymet gibi işlem gören sermaye piyasası araçlarını ise tebliğ şu şekilde açıklar,

Kamu sektörü: Devlet tahvilleri, hazine bonoları, tasarruf bonoları, gelir ortaklığı senetleridir. Özel sektör: Sabit getirili kıymetler ve değişken getirili kıymetler olarak ikiye ayrılmışlardır. Sabit getirili kıymetler tahvil ve türevlerini ifade etmektedir ve klasik tahvilleri ile çeşitleri, hisse senediyle değiştirilebilir tahviller, kara iştirakli tahviller, ipotekli borç ve irat senetleri, banka bonoları, banka garantili bonolar ve finansman bonoları, -varlığa dayalı menkul kıymetler bu gruptadır. Değişken getirili kıymetler ise hisse senedi ve türevlerini ifade etmektedir. Klasik hisse senetleri ve çeşitleri, geçici ilmühaberler, intifa senetleri, kar - zarar ortaklığı belgeleri (KOB), katılma intifa senetleri (KiS), Yatırım fonu katılma belgeleri de bu gruba girmektedir.

\section{VERGi USUL KANUNUNA GÖRE MENKUL KIYMETLERIN DEĞERLEMESi}

Kanunun ilgili maddesinde Madde 279- (4369 sayılı Kanunun 6. maddesiyle değiştirilen ve 31.12.1998 tarihinde yürürlüğe giren madde) Hisse senetleri ile fon portföyünün en az yüzde 51'i Türkiye'de kurulmuş bulunan şirketlerin hisse senetlerinden oluşan yatırım fonu katılma belgeleri alış bedeliyle, bunlar dışında kalan her türlü menkul kıymet borsa rayici ile değerlenir.

Borsa rayici yoksa veya borsa rayicinin muvazaalı bir şekilde oluştuğu anlaşılırsa değerlemeye esas bedel, menkul kıymetin alış bedeline vadesinde elde edilecek gelirin (kur farkları dahil) iktisap tarihinden değerleme gününe kadar geçen süreye isabet eden kısmının eklenmesi suretiyle hesaplanır. Ancak, borsa rayici bulunmayan, getirisi ihraç edenin kâr ve zararına bağlı olarak doğan ve değerleme günü itibariyle hesaplanması mümkün olmayan menkul kıymetler, alış bedeli ile değerlenir 
VUK'un 279.maddesi hükmüyle ayrı ayrı her bir menkul kıymetin nasıl değerleneceğini belirtmeye çalışılacaktır. Son bölümde ise muhasebeleştirilmesi açıklanacaktır.

İktisadi işletmelere dahil olan hisse senetleri ile fon portföylerinin en az \%51'i Türkiye'de kurulmuş bulunan şirketlerin hisse senetlerinden oluşan yatırım fonu katılma belgeleri alış bedelleri ile değerlenecektir. Alış bedeliyle değerlenecek olan menkul kıymetlerin dışındaki her türlü menkul kıymet borsa rayici ile değerlenir. Borsa rayiciyle menkul kıymetleri değerlerken, değerlemeden evvelki son işlem günündeki işlemlerin ortalaması alınır. Buna göre, alış bedeli bir iktisadi kıymetin satın alınması için alıcıya ödenen veya borçlanılan tutardır. Menkul kıymetin alış bedeli saptanırken menkul kıymetin edinimi için yüklenilen finansman gideri, kur farkları ve komisyon gibi giderlerden pay verilmemesi gerekmektedir.

Kıst Getiri Ölçüsü; Borsa rayiciyle değerlenmesi gereken menkul kıymetlerin borsada işlem görmüyor olması veya söz konusu menkul kıymetler borsada işlem görmekte ise, değerleme gününde herhangi bir alış- satış olmasa dahi bu menkul kıymetin alış bedeline, vadesinde kur farkları dahil edilecek gelirin iktisap tarihinden değerleme gününe kadar geçen süreye isabet eden kısmının eklenmesi ile değerleme yapılır.

Yani menkul kıymetin kıst getirisi hesaplanıp alış bedeline eklenmesidir. Kıst getiri hesaplanan kıymetler genel olarak sabit bir getiriye sahiptir.

\section{Alış Bedeli ile Değerlenen Menkul Kıymetler}

\section{a) Hisse Senetleri,}

Hisse senedi bir anonim şirketin birbirine eşit paylarından bir parçasını temsil eden, kanuni şekil şartlarına uygun, sahibine ortaklık sağlayan hukuken kıymetli bir evraktır. Şirketin faaliyeti ve karlılığı devam ettikçe sahibine kar payı getirir.Sabit ve önceden bilinen bir karlılık yoktur. Elde edilen kar payı şirketin karılığına göre değişkendir. Hisse senetleri hamiline veya nama yazılı olur.

Hisse senedi VUK 279. Maddeye göre alış bedeline göre değerlenir, Bunları satın alırken yüklenilen finansman ve kur farkları dahil edilemez. Bu ödemeler ilgili yılda gider kaydedilir.

b)

\section{Yatırım Fonu Katılma Belgeleri}

Yatırım fonu halktan katılma belgeleri karşılı̆ıında toplanan paralarla, belge sahipleri hesabına riskin dağıtılması ilkesi ve mülkiyet esaslarına göre sermaye piyasası araçları, gayrimenkul altın, ve diğer kıymetli madenler portföyü işletmek amacıyla kurulmuşlardır.

Yatırım fonu katılma belgelerinin değerlemesi VUK'un 279.maddesi gereğince, fon portföyünün en az \%51 'i Türkiye'de kurulmuş olan şirketlerin hisse senetlerinden oluşan katılım fonları alış bedeline göre değerlenir. Kanun hükmünde bu şartları sağlamayan kurumların yatırım fonları borca rayici ile değerlenir.

\section{c) Kar - Zarar Ortaklığı Belgeleri}

Kar- Zarar ortaklığı belgeleri, anonim şirketlerin kar ve zarara ortak olmak için yurt içinde ve yurt dışında satılmak üzere ihraç ettikleri menkul kıymetlerdir. Bu belgenin sabit bir getirisi yoktur. Belgeyi ihraç eden şirketin karlılı̆ına göre getiri elde edilir. Bu belgeyi ihraç edenin kar ve zararına bağlı olarak doğmakta değerleme günü itibariyle hesaplanamamaktadır. Bu tür belgelerin alış bedeli ile değerlenmesi gerekir.

\section{2- Borsa Rayici ile Değerlenen Menkul Kıymetler}

Hisse senetleri ve yukarıda belirttiğim katılma fonları dışında kalan bütün menkul kıymetlerin değerlenmesi sırasında öncelikle borsa rayicinin bulunup bulunmadığına bıkılır. Borsa rayici var ise değerleme günü itibariyle borsa rayici ile maliyet bedeli arasındaki fark kar-zarara yansıtıır. Borsa rayici açısından borsanın Türkiye'de bulunması gerekir. Uluslararası borsalarda işlem gören kıymetlerin İstanbul Menkul kıymetler borsasındaki rayiç değeri baz alınır.Aksi takdirde kıst getirisi veya alış bedeli dikkate alınır.

\section{a) Hazine Bonosu}

Hazine bonosu, kamu kesimi finansman açıklarının giderilmesi amacıyla vadesi 1 yıldan daha az olan devlet iç borçlanma senedidir. Kolayca alınıp satılabilir. Hazine bonoları IMKB Tahvil ve Bono piyasasında işlem görmektedir.Bu nedenle borsa rayici ile değerlenmesi gerekir.Hazine bonosunun edinme tarihi ile tespit edilen borsa rayiç değeri arasındaki fark kar gelir yazılır.

\section{b) Devlet Tahvili}

Anonim şirketlerin ödünç para bulmak için çıkardıkları kıymetleri eşit borç senetlerine denir.Tahviller ihraç eden tüzel kişi tarafından vade sonunda nominal değer üzerinden ödendiğinden, piyasa değerleri genellikle nominal değerin fazla altında 
veya üstünde olmaz.Tahviller, bononun orta ve uzun vadeli cinsine verilen isimdir. Türkiye'de tahvil dediğimizde ilk aklımıza gelen Devlet tahvilleridir.

Hazine bonolarından farklı olarak devlet tahvillerinde kupon bulunur. Ödeme planına göre borçlanılan tutar üzerinden kupon karşılığı faiz ödemesi yapılır. Getirisi sabittir. Önceden hesaplanabilir. IMKB Tahvil ve Bono piyasasında işlem görmektedir. Borsa rayici bulunur. Borsa rayici ile değerlenmesi gerekir. Söz konusu tahvil döviz cinsinden ise kurdaki artış gelir olarak yazııır. Borsada kayıtlı olmayan tahviller kist getiri esasına göre, tahvillerin alış bedeli ile değerleme gününe kadar oluşan gelirlerin ilave edilmesiyle değerleme yapılır.

\section{c) Özel Sektör Tahvilleri}

Borsada işlem gören özel sektör tahvillerinin varsa borsa rayici değerlenmesi gerekir. Borsada işlem görmeyen özel sektör tahvillerini aktifinde bulunduran iktisadi işletmeler kıst getiri hesaplanmak suretiyle ilgili kıymetleri değerler.

\section{d) Gelir Ortaklığı Senetleri}

Köprü,baraj, elektrik santrali, karayolu ve demiryolu gibi sivil kullanıma ait olan kamu kurum ve kuruluşlarına ait olanlarının gelirlerine ortaklık hakkı veren senetlerdir.. Ne kadar gelir sağlayacağı belli değildir. Borsa rayici ile değerlenmelidir. Fakat bu piyasa aktif değildir. Bu durumda gelir ortaklığı senetlerinin değerleri değerleme günü itibariyle bankadan veya kamu ortaklığı idaresinden öğrenilir. Kıst getiri esasına göre değerlenir. Kur farkları değerlemede dikkate alınır.

\section{e) Eurobond}

Çok uluslu bankalar ile diğer güvence veren kurumların çıkardıkları tahvillerdir. Tahvili çıkaran ülkenin dışında diğer ülkelere satılmak üzere çıkartılırlar. Yurt içinde yerleşik kişi ve kurumlara da satılabilir.

Eurobondların borsa rayici ile değerlenmesi gerekir. IMKB Tahvil ve Bono piyasasında işlem görebilmektedir. Döviz kurundaki değişiklikler değerlemede dikkate alınmalıdır. Borsada işlem görmeyen veya borsa rayici tespit edilemeyen Eurobondlar ilgili döneme isabet eden kıst getirilerinin hesaplanarak alış bedeline ilave edilmesiyle değerleme yapılır. Ortaya çıkan kur farkları kıst getirisine eklenmelidir.

\section{Kıst Getiri Hesaplanacak Menkul Kıymetler}

Alış bedeli borsa rayici ile değerlenemeyen menkul kıymetler kıst getiri hesaplanmak suretiyle değerlenecektir. Kıst getiri uygulayabilmek için söz konusu menkul kıymetin borsa rayici ile değerlemeye tabi tutulmamış olmalıdır. Değerleme günü itibariyle kıst gideri hesaplanarak değerlenecek menkul kıymetler, yabancı para cinsinden ise değerleme gününde bunlara ilişkin kur farkları VUK'a göre kıst getiriye dahil edilmesi gerekir.

a)Finansman Bonoları , b) Varlığa Dayalı Menkul Kıymetler, c) Banka Bonoları ve Banka Garantili Bonolar, d) Repo ve Ters Repo işlemleri

\section{MENKUL KIYMETLERIN VERGI USUL KANUNUNA GÖRE MUHASEBELEŞTIRILMESi}

Tek düzen hesap planına göre menkul kıymetler amaçlarına göre farklı hesaplarda izlenir. Kısa dönemde faiz geliri, kar payı sağlamak için alınan istenildiği anda elden çıkarılıp paraya dönüştürülebilen menkul kıymetler "Dönen Varlıklar" içerisinde yer alan aşağıdaki hesaplarda izlenir.

110. Hisse Senetleri,

111. Özel Kesim Tahvil, Senet ve Bonolar, Kar-Zarar ortaklı̆̆ı Belgeleri

112. Kamu Kesimi Tahvil, Senet ve Bonolar

\section{Diğer Menkul Kıymetler Yatırım fonu katılma belgeleri}

Uzun vadeli amaçlara veya yasal zorunluluklarla elde tutulan uzun vadeli menkul kıymetler. Paraya dönüştürme niteliğini kaybetmiş menkul kıymetler "Duran Varlıklar" hesap grubunda izlenir.

240. Bağıı Menkul Kıymetler, Paraya dönüştürme niteliği kaybolan menkul kıymetler

242. İştirakler, İşletmenin doğrudan veya dolaylı olarak diğer şirketlerin yönetimine ve ortaklığına iştirak etmek için edindiği hisse senetleri.

245. Bağlı Ortaklıklar, İşletmenin \%50 oranından fazla sermaye payından oy hakkına sahip olunması sermaye payını temsil eden hisse senetleri

Menkul Kıymetler edinildiğinde yukarıdaki hesaplara borç, elden çıkartıldığında ise aynı bedel ile alacak kaydedilir. Menkul kıymetlerin satın alınması sırasında oluşan giderler “659- Diğer Faaliyetlerden Olağan Gider ve Zararlar“ hesabında, menkul 
kıymetlerin satışından doğan zararlar "655- Menkul Kıymet Satış Zararı " hesabında, menkul kıymetlerin satışından doğan karlar ise "645- Menkul Kıymet Satış Karları" hesabında izlenir.

Menkul kıymetlerin sürekli olarak ve önemli ölçüde değer azalması olduğunda ortaya çıkacak zararların karşılanması amacıyla ayrılması gereken karşılıklar aşağıdaki hesaplarda izlenir.

119. Menkul Kıymetler Değer Düşüklüğü Karşılığı

241. Bağlı Menkul Kıymetler Değer Düşüklüğü Karşılığı

244. İştirakler Sermaye Payları Değer Düşüklüğü Karşılığı,

247. Bağlı Ortaklıklar Sermaye Payları değer Düşüklüğü Karşılı̆̆ı

Meydana gelen değer düşüklükleri, ilgili karşılık hesabına alacak “654- Karşılık Giderleri” hesabına borç olarak kaydedilecektir. Karşılık ayrılmış olan menkul kıymet elden çıkarıldığında değer düşüklüğü yaşamamış ise söz konusu karşıık hesabına borç kaydedilir. Karşııık tutarı ise "644- Konusu kalmayan Karşılıklar" hesabına aktarılarak kapatılır.

Borsa rayici ile değerlenen menkul kıymetlerin değerleme günündeki değerleri alış bedellerinin altına düşerse aradaki fark için karşıık ayrılıp, karşılık ayrılan tutar kurum kazancının hesaplanmasında gider olarak dikkate alınır.

Bunun dışında VUK'a göre alış bedeliyle değerlenmesi gereken menkul kıymetlere ilişkin olarak ayrılan karşlıklar matrahın tespitinde dikkate alınması mümkün değildir.

\subsection{Menkul Kıymet Alış İşlemlerinin Muhasebeleştirilmesi Örnekler}

ÖRNEK 1. X Anonim şirketinin Y aracı kurum vasıtasıyla satın aldığı hisse senetlerine ilişkin bilgiler aşağıdaki gibidir.

$\begin{array}{lc}\text { Senetlerin Nominal Bedeli } & 1.000 .000 .000,- \\ \text { Senetlerin Alış Bedeli } & 1.300 .000 .000,- \\ \text { Satın alınan Senet Adedi } & 1.000 \\ \text { Aracı Kuruma ödenen Komisyon } & 3.900 .000,-\end{array}$

$(1.300 .000 * 1000 * 0,003)$

Ödenen BSMV

195.000,-

$(3.900 .000 * 0,05)$

Hisse senedi alındığında yapılacak muhasebe kaydı

$$
\text { I }
$$

110. Hisse Senetleri

653. Komisyon Giderleri

659.Diğer Gider ve Zararlar
1.300.000.000

3.900 .000

195.000

100 Kasa

ÖRNEK 2. A Şirketi B şirketinin ihraç etmiş olduğu USD cinsinden 1 yıl vadeli yıllık faizi \%15 ve kupon faiz geri ödemesi de 1 yıl olan 100.000 USD Nominal bedelli tahvili 01.07.2011 tarihinde satın almıştır. 01.07.2011 tarihinde USD 1,40 TL, 31.12.2011 tarihinde USD 1,70 TL Buna göre tahvilin satın alma gününde değeri 100.000*1,40 = 140.000 TL'dir.

01.07.2011 ile 31.12.2011 dönemi arasında isabet eden kIst getiri $(100.000 * 0,15) *(180 / 360)=7.500$ USD $* 1,70=12.750 . T L$

Ayrıca 31.12.2011 tarihinde söz konusu tahvilin bilanço değeri 100.000*1,70=170.000.TL ile 01.07.2011 tarihli iktisap değeri 140.000.TL arasındaki 30.000.TL tutarındaki Kur Farkı değerleme gününde gelir olarak dönem kar zararına yansıtılır.

Özet olarak değerleme gününde toplam kıst getiri (Faiz geliri ve kur farkından oluşan $12.750 .+30.000=42.750$. TL olarak dönem kar-zararına intikal eder ve mali kara dahil edilir.31.12.2011 değerleme günündeki toplam değeri $(140.000+12.750+30.000)=182.750$ olur ve bilançoda bu değer yer alır.

Dönem sonu muhasebe kaydı 
$31 / 12.2011$

Özel Kesim Tah.Sen.ve Bonolar

Faiz Gelirleri

Kambiyo Karlar
42.750

12.750

30.000

\section{TÜRKIYE FINANSAL RAPORLAMA STANDARTLARI YÖNÜNDEN MENKUL KIYMETLERIN DEĞERLEMESi (TFRS)}

Tek düzen hesap planında bilançonun dönen veya duran varlıkları içinde yer alan menkul kıymet kalemleri aşağıdaki gibidir.

\begin{tabular}{|l|l|}
\hline Dönen Varlıklar & Duran Varlıklar \\
\hline 110- Hisse Senetleri & 240- Bağlı Menkul Kıymetler \\
\hline 111- Özel Kesim Tahvil Senet ve Bonolar & 242- Iştirakler \\
\hline 112- Kamu Kesimi Tahvil Senet ve Bonolar & 245- Bağlı Ortaklıklar \\
\hline 115- Diğer Menkul Kıymetler & 248- Diğer Mali Duran Varlıklar \\
\hline
\end{tabular}

Öte yandan TMS/TFRS ‘de Menkul Kıymet kalemleri önemli ölçüde değişiklik gösterir. TMS/TFRS ölç Finansal tablolarda kullanılan bilgilerin tüm kullanıcı kesimlerinin bilgi intiyacını karşılaması gerekir. Şirketler TFRS standardına iki temel değerleme yöntemi kullanır. Birincisi gerçeğe uygun değer, ikincisi ise tarihi maliyet değeridir.

Ölçümleme hükümleri gereğince menkul kıymetlere ilişkin hesap kalemleri aşağıdaki gibidir.

Finansal Varlıklar (Menkul Kıymetler)

Gerçeğe Uygun Değer Farkı Kar veya Zarara Yansıtılan Finansal Varlıklar

Gerçeğe Uygun Değer Farkı Öz Kaynaklara Yansıtılan Finansal Varlıklar

İtfa Edilmiş Maliyetle Ölçülen Finansal Varlıklar

Maliyetle Ölçülen Finansal Varlıklar

Türev Finansal Varlıklar

Finansal Varlıklar Değer Düşüklüğü Karşılığı (-)

TFRS göre finansal varlıklardan biride başka bir işletmenin öz kaynağına dayalı finansal araç, İşletmelerin başka bir işletmenin öz kaynağına dayalı olarak ihraç ettiği finansal araçlarına sahip olması, Bu araçları varlık olarak aktifinde bulundurmasıdır. Hisse senetleri bir örnektir.

\subsection{Finansal Varlıkların Değerlemesi (Hisse Senetleri)}

Finansal varlıklar, (hisse senetleri dahil) ilk muhasebeleştirilmeleri sırasında gerçeğe uygun değeri üzerinden değerlemeye tabii tutulurlar. Finansal varlık alım satım amaçlı olarak izlenmeyecekse söz konusu gerçeğe uygun değere, Finansal varlığın edinimi veya finansal borcun oluşumu ile doğrudan ilişkilendirile bilen masraflar dahil edilebilir.

Gerçeğe Uygun Değer, Alım satım amaçlı olarak sınıflandırılan bir finansal varlıktan (hisse senetleri) doğan kazanç ve kayıplar değerleme gününde dönem kar/zararına yansıtılır.

ÖRNEK 1. ABC İşletmesi iktisap tarihi 01.12.2012 ve iktisap bedeli 10.000 TL olan Duru şirketine ait olan hisse senetlerini kısa vadeli sermaye kazancı sağlamak, ve borsanın yükselmesinden dolayı satın almıştır.

Söz konusu hisse senedinin IMKB 'de 31.12.2012 tarihinde değeri 12.000 TL'dir.

Bu hisse senetleri 01.03.2013 tarihinde 15.000 TL'ye satılmıştır.

çözÜM: Yakın bir tarihte satılmak amacıyla alındığı için, Kısa dönemde kar etme eğilimi kesin bilgidir. Bu nedenle bu hisse senetleri Gerçeğe uygun değer ile değerlemeye tabii tutulması ve gerçeğe uygun değer farkının dönem kar zararına yansıtılması gerekir. 
Muhasebe Kaydı ise

01.11 .2012

GERÇEĞE UYGUN DEĞER FARKI YANSITILAN 10.000

FINANSAL VARLIKLAR

BANKALAR

10.000

Iktisap tarihinde işletmenin aktifine 10.000 TL ile kaydedilen hisse senetlerinin 31.12.2012 tarihinde iMKB' deki değeri 12.000 TL 'dir.2000 TL gerçeğe uygun değer farkının değerleme gününde dönem kar zararını yansıtılır.
GERÇEĞE UYGUN DEĞER FARKI YANSITILAN
2.000

FINANSAL VARLIKLAR

DIĞER ÇEŞiTLI GELIR VE KARLAR

2.000

Söz konusu hisse senetlerinin izleyen yılda 01.03.2013 yılında 15.000 TL'ye satılması nedeniyle TFRS kaydı şöyle olacaktır. Ticari karın hesabında bir önceki yıl gerçeğe uygun değer farkı olan 2.000 TL dönem kar zararına yansıtıldığından satış tarihinde menkul kıymet satış karı $3.000 \mathrm{TL}$ 'dir.

01.03 .2013

\begin{tabular}{llc} 
BANKALAR & \multicolumn{2}{c}{15.000} \\
& GERÇEĞE UYGUN DEĞER FARKI YANSITILAN & 12.000 \\
& FINANSAL VARLIKLAR & \\
& FINANSAL VARLIKLAR SATIŞ KARLARI & 3.000
\end{tabular}

Yukarıdaki örneğe göre VUK'a göre menkul kıymet satış karı,hisse senetlerinin elden çıkarıldığı döneme ait olduğundan bir önceki hesap döneminde matrahın hesaplanmasında dikkate alınmayan 2.000 TL 'nin cari dönemin vergi matrahına beyanname üzerinde eklenmesi gerekir.Menkul kıymet satış karı hisse senetlerinin elden çıkarıldığı hesap döneminde $2.000+3.000=5.000 \mathrm{TL}$ 'dir.

Maliyet ile değerlemeye tabii finansal varlıklar; TMS 39 uyarınca satılmaya hazır finansal varlıklar içerisinde toplanan ve gerçeğe uygun değeri tespit edilebilen finansal varlıklar gerçeğe uygun değerlemeye tabi tutulur. Değerleme farkları öz kaynaklarda muhasebeleştirilir.

Bu sınıflandırmada satılmaya hazır finansal varlıkların raporlanan ve gerçeğe uygun değeri tespit edilemeyen finansal varlıklar ise maliyet değeri ile değerlemeye tabii tutulur.

ÖRNEK 1. A İşletmesi 10.11.2011 tarihinde 8.000 iktisap bedeli ile (C) hisse senedi satın almıştır.Aynı tarihte maliyet ile ölçülen finansal varlıklar (SATILMAYA HAZIR FiNANSAL VARLIKLAR) hesabına 8.000 TL iktisap bedeli üzerinden kaydetmiştir.

Söz konusu hisse senedinin borsa rayici bulunmadığı gibi piyasa değerini tespit edilmesini sağlayıcı nitelikte bir bilgi bulunmamaktadır.

çözÜM 1. Söz konusu hisse senedinin kısa sürede elden çıkarılacağı belirtilmediğinden iktisap nedeni alım satım amaçlı değildir. Uzun süreli yatıım amaçlı olarak iktisap edildiği anlaşılmaktadır. Borsada işlem görmemesi ve gerçeğe uygun değer tespitine uygun verilerin bulunmamasından dolayı "Satılmaya Hazır Finansal Varlıklar" olarak sınıflandırılır ve maliyet bedeline göre değerlemeye tabii tutulur.

10.11.2011

MALIYETLE ÖLÇÜLEN FINANSAL VARLIKLAR 8.000

(Satılmaya Hazır Finansal Varlıklar)

BANKALAR

8.000 


$\begin{array}{ll}{ }_{\text {MALIYETLE ÖLÇÜLEN ÖNEMLI ETKI }}^{31.12 .2011} & 8.000 \\ \text { TASIMAYAN VARLIKLAR } & \end{array}$

MALIYETLE ÖLÇÜLEN FINANSAL VARLIKLAR
.000

8.000

\subsection{Tahsil Senet ve Bonoların TMS/TFRS Kapsamında Değerlemesi}

TMS/TFRS uyarınca tahvil senet ve bonolar itfa edilmiş maliyet değeri ile değerlemeye tabidir.

İtfa edilmiş maliyet değeri; Finansal varlık veya borcun ilk muhasebeleştirmeleri sırasında ölçülen değerinden anapara geri ödemeleri düşüldükten sonra anılan ilk tutar ile vadedeki tutar arasındaki farkın, etkin faiz yöntemi kullanılarak hesaplanan birikmiş itfa payı düşüldükten sonra, değer düşüklüğü yada tahsil edilememe durumuna ilişkin her türlü indirimin yapılmasından kalan tutardır. Doğrudan bir karşılık hesabı kullanılır.

Etkin Faiz Yöntemi ve Oranı; Finansal varlık veya borcun itfa edilmiş maliyetlerinin hesaplanması ile ilgili faiz ve giderlerinin ilişkili olduğu döneme dağıtılması yöntemidir.Faiz oranı ise net defter değerine indirgeyen oranıdır.

\section{3.işstiraklerdeki Yatııımların Değerlemesi}

İştiraklerdeki yatırımlar öz kaynak yöntemi uygulanmak suretiyle değerleme tabi tutulur.

Öz kaynak Yöntemi; iştirak yatırımı başlangıçta elde etme maliyeti ile kaydedilir. İktisap tarihinden sonra ise yatırımcının yatırım yapılan işletmenin kar yada zararındaki payı finansal tablolara yansıtılmak üzere defter değeri azatlılar ve ya arttırılır. Yatırım yapılan bir iştirakten alınan kar payları vb. dağıtımlar yatırımın değerini azaltır.

Bir iştirak yatırımı, yatırımcı iştirakteki önemli etkinin bittiği (yatıım yapılan işletmenin oy hakkının \%20'nin altına indiği) tarihten itibaren öz kaynak yöntemini uygulamayı bırakır ve yatırımını TMS 39’a göre muhasebeleştirir.

\section{VUK ve TFRS KARŞILAŞTIRMALI UYGULAMA}

UYGULAMA 1. Duru Ticaret Ltd. Şti. 31.12.2007 Tarihli Mizanı

\begin{tabular}{|l|c|c|}
\hline HESAP ADI & BORÇ BAKIYE & ALACAK BAKIYE \\
\hline 100 KASA & 1.400 & \\
\hline 110 MENKUL KIYMETLER & 20.000 & \\
\hline 120 ALICILAR & 18.000 & \\
\hline 153 TiCARI MALLAR & 15.000 & \\
\hline 255 DEMiRBAŞLAR & 16.000 & \\
\hline 257 BiRiKMiŞ AMORTiSMANLAR & & 6.400 \\
\hline 320 SATICILAR & & 17.000 \\
\hline 500 SERMAYE & & 26.000 \\
\hline 570 GEÇMiŞ YILLAR KARLARI & & 5.000 \\
\hline 600 SATIŞLAR & 56.000 & \\
\hline 621 SATIŞLARIN MALIYETi & & 4.000 \\
\hline 645.MENKUL KIYMET SAT.KAR & & \\
\hline 770 GENEL YÖNETiM GiDERLERi & 12.000 & \\
\hline (3.200 TL'si Amortisman Gideridir) & $\mathbf{1 3 8 . 4 0 0}$ & $\mathbf{1 3 8 . 4 0 0}$ \\
\hline TOPLAM & & \\
\hline
\end{tabular}

110 Menkul Kıymetler hesabının detayı şu şekildedir.

\begin{tabular}{|l|l|c|c|c|}
\hline Hisse Senedi & Edinme Tarihi & Maliyet Değeri & Değerleme Ölçüsü & $\mathbf{3 1 . 1 2 . 2 0 0 7}$ Değeri \\
\hline KLM Eurobond & 18 Eylül 2007 & $8.000 \mathrm{TL}$ & Borsa Değeri & $12.000 \mathrm{TL}$ \\
\hline Lara Ticaret A.Ş. & 14 Aralık 2006 & $5.000 \mathrm{TL}$ & Maliyet Değeri & $5.000 \mathrm{TL}$ \\
\hline Asya Paz A.Ş. & 14 Aralık 2006 & $3.000 \mathrm{TL}$ & Maliyet Değeri & $3.000 \mathrm{TL}$ \\
\hline & & & & $\mathbf{2 0 . 0 0 0 ~ T L}$ \\
\hline
\end{tabular}


- $\quad$ KLM Eurobond uluslar arası piyasalarda ve IMKB'de işlem gören bir menkul kıymettir. Duru Ticaret A.Ş.bu hisseleri kısa süreli kar elde etmek borsanın yükselişine göre elden

- $\quad$ Lara Ticaret A.Ş.'nin hisseleri ilmuhaber şeklindedir. Bu şirket kurulurken şirkete sermaye desteği sağlamak için elde edilmiştir.

- Şirket Asya Paz.A.Ş’nin \%5'ini elinde bulundurmaktadır.15 Aralık 2007 tarihinde bu şirketin \%10'na sahip olan Aydın Ticaret A.Ş. bu hisseleri net 14.000 TL'ye elden çıkarmıştır.

- İşletmedeki stokların tahmini satış tutarı $19.000 \mathrm{TL}$ ve tahmini satış gideri \%5'dir.

- Alıcılar ve Satıcılar hesabı senetsiz ve vadeli alım satımlardan oluşmaktadır. Alıcılar hesabının itfa edilmiş maliyet bedeli 16.750 TL, Satıcılar hesabının itfa edilmiş maliyet bedeli 16.200 TL'dir

- Demirbaşlarda değer düşüklüğü gerçekleşmediği ve demirbaşların gerçeğe uygun değerinde finansal tabloları etkileyecek önemli bir değişiklik yoktur. Tüm demirbaş alımını 12 Kasım 2006 tarihinde almıştır.Maliyet Değeri 16.000 TL, ekonomik ömrü 5 yıl,2007 yılı Amortisman 3.200 TL, Birikmiş Amortismanı 6.400 TL

- Satışların 12.000 TL'lik kısmi ile ilgili fatura kesildiği halde sözleşme şartları yerine getirilememiş yani mallar müşteriye teslim edilememiştir. Bu ticari malın maliyeti $7.000 \mathrm{TL}$

- Vergi oranı \%20 'dir.

İşletmenin 01.01.2007-31.12.2007 dönemi Vergi Mevzuatına uygun

GELIR TABLOSU

\begin{tabular}{|l|c|}
\hline SATIŞLAR & 80.000 \\
\hline (SATILAN MALIN MALIYETI) & $(56.000)$ \\
\hline BRÜT SATIŞ KARI & 24.000 \\
\hline (GENEL YÖNETIM GIDERI) & $(12.000)$ \\
\hline DIĞER GELIRLER & 4.000 \\
\hline DÖNEM KARI & 16.000 \\
\hline (VERGI KARŞILIĞI) & $(3.200)$ \\
\hline DÖNEM NET KARI & $\mathbf{1 2 . 8 0 0}$ \\
\hline
\end{tabular}

İşletmenin 01.01.2007-31.12.2007 dönemi Vergi Mevzuatına uygun BiLANÇOSU

\begin{tabular}{|l|l|l|c|}
\hline 100 KASA & 1.400 & 320 SATICILAR & 17.000 \\
\hline 110 MENKUL KIYMETLER & 20.000 & & \\
\hline 120 ALICILAR & 18.000 & 370 VERGI KARŞILIĞI & 3.200 \\
\hline 153 TiCARI MALLAR & 15.000 & 500 SERMAYE & 26.000 \\
\hline 255 DEMIRBAŞLAR & 16.000 & 570 GEÇMIŞ YIL KARI & 5.000 \\
\hline 257 BiR.AMORTISMANLAR & $(6.400)$ & 590 DÖNEM NET KARI & 12.800 \\
\hline \multicolumn{1}{|c|}{ AKTiF TOPLAMI } & $\mathbf{6 4 . 0 0 0}$ & PASIF TOPLAMI & $\mathbf{6 4 . 0 0 0}$ \\
\hline
\end{tabular}

\subsection{MENKUL KIYMETLERIN TFRS DÜZELTMELERI (TMS32-39)}

110 Menkul Kıymetler Gerçeğe Uygun Değer Farkı Kar(Zarar)'a Yansıtılanlar

\begin{tabular}{|l|l|l|c|}
\hline \multicolumn{1}{|c|}{ Hisse Senedi } & Maliyet Değeri & $\begin{array}{l}\text { Gerçeğe Uygun } \\
\text { Değeri }\end{array}$ & $\begin{array}{l}\text { VUK/TMS FARKI } \\
\text { VARMI }\end{array}$ \\
\hline KLM Eurobond & $8.000 \mathrm{TL}$ & $12.000 \mathrm{TL}$ & YOK \\
\hline Asya Paz A.Ş. & $3.000 \mathrm{TL}$ & $7.000 \mathrm{TL}$ & VAR \\
\hline
\end{tabular}

Diğer Menkul Kıymetler

\begin{tabular}{|l|c|c|c|}
\hline Hisse Senedi & Maliyet Değeri & $\begin{array}{c}\text { Gerçeğe Uygun } \\
\text { Değeri }\end{array}$ & $\begin{array}{c}\text { VUK/TMS FARKI } \\
\text { VARMI }\end{array}$ \\
\hline Lara Ticaret A.Ş. & $5.000 \mathrm{TL}$ & YOK & YOK \\
\hline & & & \\
\hline
\end{tabular}


31.12.2007

110 Hisse Senetleri

4.000

110.10. GUD Farkı K/Z'a Yansıtılanlar

649 Diğer Olağan Gelir ve Karlar

4.000

649.10 GUD Karlar

Lara Tic.A.Ş. hisseleri ilgili işletmenin kısa süreli bir planı bulunmamaktadır.Bu nedenle de bu hisse senetlerinin uzun süreli mali duran varlıklarda raporlanması daha uygundur.

31.12.2007

249 Diğer Mali Duran Varlıklar

5.000

110 Hisse Senetleri

5.000

Alıcılar, Satıcılar, Stoklar, Duran Varlıklar ve Satışların TFRS'ye uygun Düzeltmeleri yapılmıştır. Sonuçları aşağıda Bilanço ve Gelir Tablolarına yansıtılmıştır.

Ertelenmiş Vergi Hesaplaması

\begin{tabular}{|l|l|l|l|l|}
\hline & VUK & TFRS & FARK & $\begin{array}{l}\text { Ertelenmiş Vergi } \\
\text { Alacağı Borcu }\end{array}$ \\
\hline Menkul Kıymetler & 20.000 & 19.000 & 1.000 & 200 \\
\hline Ticari Alacaklar & 18.000 & 16.750 & 1.250 & 250 \\
\hline Stoklar & 15.000 & 22.000 & $(7.000)$ & $(1.400)$ \\
\hline Diğer Mali D.Varlık. & 0 & 5.000 & $(5.000)$ & $(1.000)$ \\
\hline Demirbaşlar & 9.600 & 12.400 & $(2.800)$ & $(560)$ \\
\hline Ticari Borçlar & 17.000 & 16.200 & $(800)$ & $(160)$ \\
\hline Ertelenmiş Gelirler & 0 & 12.000 & 12.000 & 2.400 \\
\hline Geçmiş Yıllar Karları & 5.000 & 7.800 & 2.800 & 560 \\
\hline & & & & $\mathbf{2 9 0}$ \\
\hline
\end{tabular}

31.12.2007

286 Ertelenmiş Vergi Alacağı 290

691 Vergi Karşılığı $\quad 290$

691.10 Ertelenmiş Vergi Geliri

İşletmenin 01.01.2007-31.12.2007 dönemi ait TFRS'ye uygun GELIR TABLOSU

\begin{tabular}{|c|c|}
\hline SATIŞLAR (80.000-12.000) & 68.000 \\
\hline (SMM) (56.000-7000) & $(49.000)$ \\
\hline BRÜT SATIŞ KARI & 19.000 \\
\hline $\begin{array}{l}\text { (GENEL YÖNETIM GIDERI) } \\
\text { Reeskont Gideri } 1.250\end{array}$ & (13.250) \\
\hline $\begin{array}{l}\text { DiĞER GELIRLER } \\
\text { Reeskont Geliri } 800 \\
\text { Menkul Kıymet Satış Karı } 4.000 \\
\text { Diğer Olg.Gelir ve Karlar } 4.000\end{array}$ & 8.800 \\
\hline DÖNEM KARI & 14.550 \\
\hline (VERGI KARŞILIĞI) & (2.910) \\
\hline DÖNEM NET KARI & 11.640 \\
\hline
\end{tabular}


İşletmenin 01.01.2007-31.12.2007 dönemine ait TFRS'ye uygun BiLANÇOSU

\begin{tabular}{|l|l|l|c|}
\hline 100 KASA & 1.400 & 320 SATICILAR & 16.200 \\
\hline 110 MENKUL KIYMETLER & 19.000 & & \\
\hline 120 ALICILAR & 16.750 & 370 VERGi KARŞILIĞI & 3.200 \\
\hline 153 TICARI MALLAR & 15.000 & 379 ERTELENMIŞ GELIRLER & 12.000 \\
\hline 157 YOLDAKI MALLAR & 7.000 & 500 SERMAYE & 26.000 \\
\hline 255 DEMIRBAŞLAR & 12.400 & 570 GEÇMIŞ YIL KARI & 7.800 \\
\hline 286 ERTELENMIŞ VER.ALC & 290 & 590 DÖNEM NET KARI & 11.640 \\
\hline \multicolumn{1}{|c|}{ AKTiF TOPLAMI } & $\mathbf{7 6 . 8 5 0}$ & PASIF TOPLAMI & $\mathbf{7 6 . 8 5 0}$ \\
\hline
\end{tabular}

\section{VERGI USUL KANUNU VE TÜRKIYE FINANSAL RAPORLAMADAKI DEĞERLEME FARKLILIKLARI}

Vergi Usul Kanunu açısından değerleme konusu varlık değerlemede teklik ilkesi kullanılır. Vergi hukukunda değerleme vergi alacağını güvence altına almaktadır. Kesin ve objektif esaslara dayanır.

Türkiye muhasebe standartlarındaki hükümler, vergi düzenlemelerinde önemli ölçüde farklılıklar içermektedir. Standartlar ile vergi kanunlarının amaçları farklıdır. Standartlar daha çok yatırımcılar, borç verenler, ortaklar için raporlamayı öne çıkarır. Standartlara göre Finansal Varlıklar büyük ölçüde kesin açıklamalardan çok tahminlere yargılara ve yöntemlere dayanır.

VUK'a göre “Değerleme Esasları" tutulan kayıtlarda kıymetlerin nasıl değerlendirileceği ayrıntılı olarak ele alır. 1961'den beri tüm işletmeler bahse konu değerleme esaslarını temel alarak tablolarını hazırlamışlardır.Yeni TTK muhasebe standartlarını esas aldığı ve muhasebe standartları da temelde muhasebeleştirme ilkelerine dayandığı için kurala dayalı vergi uygulamaları ile "ilkeye dayalı" muhasebe uygulamalarının birbiriyle uyumsuz olduğu hedef ve sonuçlarının farklılaştığı görülmüştür

VUK'taki değerleme ile varlıkları ve borçları kayıtlara alma işletmenin gerçek mali durumu ve performansını (şeffaflık prensibi) göstermekten çok işletmenin vergi matrahını belirlemeye yöneliktir. Halbuki günümüzde işletme ortakları dahil,işletme ile menfaat ilişkisi içindeki tüm ilgilileri, değişen ekonomik ortamlarda şirketlerin gerçeğe en yakın mali durumu ile ilgilenmektedirler.

TFRS'ının baktığımızda veya vergi kanunlarına baktığımızda başlangıçta iktisadi işlemlerin tahakkuk esasına göre yapıldığı fark olmadığı görülüyor. Standartlarda güvenilir bir ölçüm yapılmışsa gelir ve giderin muhtemel olması tahakkuk için yeterli sayılmışken, vergi mevzuatımızda bir kesinlik aranmaktadır.

\section{Türkiye Muhasebe Standartları ile vergi kanunlarının farklılıklarını şöyle sıralayabiliriz.}

a) Standartlar yatırımcılar, kredi verenler ve ortaklar içindir. Vergi Usul Kanunu ise vergi güvenliği temelli olan daima ortak olan devlet içindir.

b) Vergi Usul Kanunu, kanuni düzenlemeleri ve kuralları herkesin uygulayacağı şekilde düzenlerken, Muhasebe Standartlarında yaklaşım ilkeseldir. İşletme yöneticilerinin kararları ve niyetlerine göre uygulanacak yöntemde ortaya çıkmış olur. Finansal raporlar büyük ölçüde kesin açıklamalardan çok tahmin ve yargılara ve yöntemlere dayanır.

c) Vergi Usul Kanunu kıymetlerin değerlemesinde ilgili kıymeti bir tek değerleme usulü ile değerler. Muhasebe standartlarında ise alternatifli olarak değerleme ölçülerine izin verir. Kıymetin değerlemesi de alternatiflerin uygulanması ticari karın tutarını etkiler

d) Vergi Usul Kanunu bir kısım finansal araçlar dışında anılan kıymetlerin güncel değerine yer vermez, kıymetin işletmedeki değeri baz alınır. İşletme dışına çıkıncaya kadar da o değer baz alınır. Oysa Standartlarda en önemli amaç varlıklar ve yükümlülüklerin tamamının gerçeğe uygun değerine tespit etmektir.

e) Vergi Usul Kanununda her kıymet tek tek değerlenir. Standartlar da ise kıymetin bulunduğu grup açısından bir ölçümleme yapılır.

f) Vergi Usul Kanunu ve vergi uygulamaları "gerçekleşme" olmadan karşılık yada giderleştirmeye izin vermediği halde, Standartlar işletmenin önceden olumsuz beklentilerine de karşlık ayırır. Bu sayede önceden ihtiyatlılığın gereği olarak gelir azaltılabilmektedir.

\section{SONUÇ}

Menkul kıymetler VUK'a göre hisse senetleri alış bedeli ile değerlenir. Bilanço günü değeri ile tasarruf günü değerine yükseltilmesi söz konusudur. İştirakler,bağlı ortaklıklar ve bağlı menkul kıymetler 279.maddeye göre alış bedeli ve itibari değere göre değerlemeye tabidir. 
Menkul Kıymetler TFRS'na göre elde etme maliyeti ile değerlenir. Satın alma bedeline bağlı olarak giderler maliyete dahil değildir. Bilanço gününden önceki ortalama ve elde etme maliyetlerinden düşük olanı ile değerleme yapılacaktır. Devlet Tahvili, hazine bonosu iktisap tarihi ile bilanço günü arasındaki fark gelir tahakkukuna alınır. Piyasalarda işlem görmeyen kıymetlerin elde etme maliyetlerine göre değer kıymetleri halinde rayiç bedel ile değerlenir.

TFRS'na göre Iş̧tirakler, bağlı ortaklıklar ve bağlı menkul kıymetler, elde etme maliyeti caridir.Borsada işlem görmeyenler için net defter değeri düşükse bu bedel esas alınır. Borçlanma maliyetleri (faiz,kur farkı,vade farkı) maliyete dahil edilmez.

TFRS mevzuatı ihtiyatılık, süreklilik açılarından değerlemeye yaklaşarak sermaye piyasalarında menkul kıymet ihraç etmiş şirketlerin karlarını olduğundan yüksek göstermelerini önleyici ve gelecekte oluşacak muhtemel giderlerini de içerecek şekilde konuyu düzenlemiştir.

Bu çalışmada genel olarak menkul kıymetlerin neler olduğunun genel çerçevesi belirtilmiştir. Vergi Usul Kanunu ve Türkiye Finansal Raporlama Standartları değerleme hükümleri özet bir şekilde ele alınmıştır. işletmeler için önemli olan menkul kıymetlerin değerlemesinin, Vergi Usul Kanunu ve Türkiye Finansal Raporlama Standartları yönünden incelenmesi ve raporlamaya etkilerinin ortaya çıkartılmaya çalışılmıştır.

\section{KAYNAKLAR}

http://www.kgk.gov.tr/content detail-208-513-son-halleriyle-standartlar.html (Erişim Tarihi:18.03.2017)

HELVACıOĞLU, Serhan, (2015), BDO Denet İş Yatırım Sunumları

YALÇIN, Hüseyin, Kazım METiN, (1996), İşletmeye Dahil iktisadi kıymetleri Değerleme,

http://www.verginet.net (Erişim Tarihi:15.03.2017)

ERDOĞAN, Murat, 2011, VUK'ndan TFRS'na Geçiş Rehberi

YILMAZ, Kazım, (2012 ), Değerleme

AKBULUT, Akın, (2012) Karşılaştırmalı TMS/TFRS - Vergi Uygulamaları

KIZIL,Ahmet ,Mehmet M.FIDAN, Cevdet KIZIL,İrem KESKIN, TMS - TFRS Uygulamalar ve Yorumlar

GÖKÇEN,Gürbüz,Başak ATAMAN, Akgul Cemal ÇAKICI,Türkiye Muhasebe Standartları Uygulamaları

FIRAT,Furkan, Vergi Sorunları Dergisi Aralık 2014 , Sayı.315 